\title{
A Multiport Electric Energy Routing Scheme Applied to Battery Energy Storage System
}

\author{
Guanglin Sha, ${ }^{1}$ Qing Duan, ${ }^{1}$ Wanxing Sheng, ${ }^{1}$ Aiqiang Pan, ${ }^{2}$ Zhe Liu, ${ }^{2}$ Chunyan Ma, \\ Caihong Zhao, ${ }^{1}$ Jiaxun Teng $\mathbb{D}^{1}{ }^{1}$ Lumin $\mathrm{Fu}^{3}$ and Yi Zheng ${ }^{3}$ \\ ${ }^{1}$ Beijing Key Laboratory of Distribution Transformer Energy-Saving Technology, China Electric Power Research Institute, \\ Haidian District, Beijing 100192, China \\ ${ }^{2}$ State Grid Shanghai Municipal Electric Power Company, No. 171, Handan Road, Shanghai 200437, China \\ ${ }^{3}$ State Grid Shanghai Pudong Electric Power Supply Company, Pudian Road No. 111, Shanghai 200122, China
}

Correspondence should be addressed to Jiaxun Teng; tengjiaxun@qq.com

Received 5 November 2020; Accepted 1 August 2021; Published 26 August 2021

Academic Editor: Kamran Iqbal

Copyright (C) 2021 Guanglin Sha et al. This is an open access article distributed under the Creative Commons Attribution License, which permits unrestricted use, distribution, and reproduction in any medium, provided the original work is properly cited.

In this paper, the research status of topology and control strategy of energy storage grid-connected system is analyzed, and aiming at the working characteristics of the repurposed battery, a cascade power electronic transformer (CPET) with independent DC output is proposed. The working principle of current fed isolated bidirectional DC-DC converter (CF-IBDC) and cascaded $\mathrm{H}$-bridge (CHB) is analyzed, and the decoupling control strategy is designed. In this paper, a hierarchical control strategy is designed for the repurposed battery energy storage (RBES) grid-connected system based on CPET, which consists of three layers: energy layer, power layer, and state of charge (SOC) layer. The energy layer responds to active and reactive power scheduling instructions, the power layer controls the grid-connected current and tracks the grid voltage, and the SOC layer equates the charged state of repurposed batteries. A $3 \mathrm{MVA} / 12 \mathrm{kV}$ three-phase grid-connected simulation system was established, and a $1 \mathrm{~kW}$ single-phase system experiment platform was designed. The simulation and experimental results can verify the correctness of the theoretical analysis and the feasibility of the control strategy.

\section{Introduction}

In recent years, the proportion of renewable energy in the power system has gradually increased, but its output power is characterized by volatility and intermittency, which limits the capacity of renewable energy generation to connect to the grid on a large scale $[1,2]$. Supporting battery energy storage system can effectively improve the ability of power grid to accept renewable energy [3-6]. The cost factors of large-capacity converters and energy storage batteries limit the promotion and application of the battery energy storage system, while repurposed lithium batteries and link topology provide a new idea to solve the cost problem [7].

The echelon utilization of the retired power battery of electric vehicles is to design the repurposed battery cells into a battery pack after screening. Due to the limitation of the production process of the battery itself, the actual capacity, internal resistance, voltage, and other performance parameters of the battery are different to some extent, which is collectively referred to as the inconsistency of the battery [8-10]. After long-term use of repurposed battery packs, the battery performance degrades, and the single battery parameters will show obvious dispersion, which is manifested as obvious capacity difference, internal resistance difference, and voltage difference between batteries [11-13]. The existence of inconsistencies in battery cells leads to uneven charging and discharging within the battery pack. If not controlled, longterm operation will greatly reduce the reliability and security of the battery energy storage system [14]. In the design of large-capacity energy storage system, the battery pack needs to be continuously charged and discharged, and the inconsistency of discreteness will lead to a large difference in the decay speed of battery parameters, thus accelerating and amplifying the inconsistency of the battery pack $[15,16]$. In 
the echelon utilization of repurposed batteries, the inconsistency problem will be solved from two aspects. First, we select batteries with small differences to form the battery pack and build the battery management system to reduce the inconsistency of batteries within the same group. Second, we select the appropriate electrical topology structure and design the balanced control, which can slow down the rate of battery performance decline.

PET integrates voltage transformation, high-frequency electrical isolation, and flexible power flow control, making it a research direction of topological structure of battery energy storage system. For the PET used in distributed energy storage methods, the control targets are mostly DC link voltage equalizing control and isolation level parallel submodule power equalizing control. Reference [17] presented cell and phase balance for power and energy of a 10-cell multilevel inverter cascaded $\mathrm{H}$-bridge. The $\mathrm{CHB}$ inverter control for each stage leg used the type of phase-shifted carrier. The control strategy based on the idea of a virtual synchronous generator is used on the way to balance the power and energy distributed among cells in the same phase and between phases. Reference [18] described a $14.14 \mathrm{kV}, 2 \mathrm{MW}$, and $1000 \mathrm{Ah}$ system with fortyfive Li- (lithium-) ion battery units. The system is based on a cascaded H-bridge multilevel PWM converter with star configuration focusing on the active power balancing of individual converter cells and a control system is proposed which consists of active power control and SOC balancing control (interphase SOC balancing control and phase-phase SOC balancing control). In [19], two SOC balancing techniques are proposed for an electrical vehicle charging station which is based on a grid-tied cascaded CHB multilevel converter. The first proposed technique uses the redundant states of the CHB converter to generate different $\mathrm{AC}$ voltages to balance the SOCs of the CHB cells. In the second proposed technique, the information of AC input current is employed to design the switching states at each quarter of the period. Hu et al. [20] proposed a novel hybrid power converter topology based on $\mathrm{CHB}$ and matrix converter. The $\mathrm{CHB}$, as the energy control unit, can be used to balance the voltage/SOC of battery packages individually and significantly improve the modularity, stability, and safety of EV system. Kandasamy et al. [21] investigated a module level SOC balancing control in cascaded CHB based BESS using multidimensional modulation technique. SOC can be equalized between the battery modules in a phase leg of $\mathrm{CHB}$ with the proposed control strategy.

Aiming at the inconsistency problem of repurposed batteries, this paper presents a cascade power electronic transformer with independent DC outputs. The RBES combines the control target and topology structure to design the three-layer control architecture including energy layer, power layer, and SOC layer. The energy layer is used to respond to scheduling instructions and suppress power fluctuations, peak load clipping, and reactive power compensation. The power layer distributes active power based on SOC and divides reactive power equally to make full use of system capacity. SOC layer equalizes the charged state of decommissioned lithium battery to avoid short plate effect and stabilize the voltage of high voltage bus. The security and reliability of the RBES are enhanced.

\section{System Composition and Power Flow Analysis}

2.1. System Composition. The echelon RBES grid-connected system of the CPET proposed in this paper is shown in Figure 1. The system adopts a two-stage structure, with an independent DC output terminal to access the repurposed battery, and the topology is divided into the DC cell group consisting of cascade CF-IBDC module and the DC-AC consisting of $\mathrm{CHB}$ module. Based on a $3 \mathrm{MVA} / 12 \mathrm{kV}$ medium voltage grid system, considering the trade-off among system cost, life, passive components, switching devices, frequency, and power quality during design progress, the number of each phase containing $\mathrm{H}$-bridge cell is $N=4$, and the number of CF-IBDC cell modules contained in the DC group corresponding to each $\mathrm{H}$-bridge is $M=4$. Within the DC-DC unit, the high-voltage side of the CF-IBDC adopts series structure to obtain the high-voltage bus voltage, $V_{\text {dcia }}=3000 \mathrm{~V}$, and the low-voltage side of the converter is connected to the repurposed battery module, respectively, to realize independent energy balance control. The $\mathrm{H}$-bridge module constitutes a multilevel cascade system, realizing the grid-connected control.

2.2. Cascade H-Bridge Analysis. The CHB topology is shown in Figure 1. All modules are in series structure; that is, the output current of the modules is the same, and the power distribution between the modules will be determined by their output voltage. In order to realize the independent control of active and reactive power, a discrete Fourier transform phase-locked loops (PLL) method is adopted. This method is only based on single-phase grid voltage signal and can extract basic phase, frequency, and amplitude information from any signal. The active power and reactive power can be decoupled by coordinate transformation, and then they can be controlled independently. The distribution of active power and reactive power of phase A among $N$ $\mathrm{H}$-bridge modules is illustrated in Figure 2. The same analysis is also carried out for phase B and phase C, which will not be repeated in this paper.

In the coordinate analysis, considering the relative stability of the grid voltage, the synchronous signal is $V_{\text {ga }}$. The $\alpha$-axis in the $\alpha \beta$ coordinate system is in phase with the grid voltage, and the $\beta$-axis lags the $\alpha$-axis by $90^{\circ}$. The $d$-axis in the $d q$ coordinate system is aligned with the grid voltage through PLL control technology, and $q$-axis lags $d$ axis by $90^{\circ}$, as shown in Figure 2(a). The grid voltage components in the $\alpha \beta$ coordinate system and the $d q$ coordinate system are given by the following equations, respectively:

$$
\begin{aligned}
& \left\{\begin{array}{c}
v_{\mathrm{ga} \_a}=V_{\mathrm{ga}} \cdot \sin (\omega t), \\
v_{\mathrm{ga} \_\beta}=-V_{\mathrm{ga}} \cdot \cos (\omega t),
\end{array}\right. \\
& {\left[\begin{array}{c}
v_{\mathrm{ga} \_d} \\
v_{\mathrm{ga} \_q}
\end{array}\right]=\left[\begin{array}{cc}
\sin (\omega t) & -\cos (\omega t) \\
\cos (\omega t) & \sin (\omega t)
\end{array}\right]\left[\begin{array}{c}
v_{\mathrm{ga} \_d} \\
v_{\mathrm{ga} \_q}
\end{array}\right],}
\end{aligned}
$$

where $\omega$ is the grid voltage frequency, $V_{\mathrm{ga}}$ is the amplitude of phase-A grid voltage, and $v_{\text {ga } d}=V_{\text {ga }} ; V_{\text {ga }-q}=0$. 


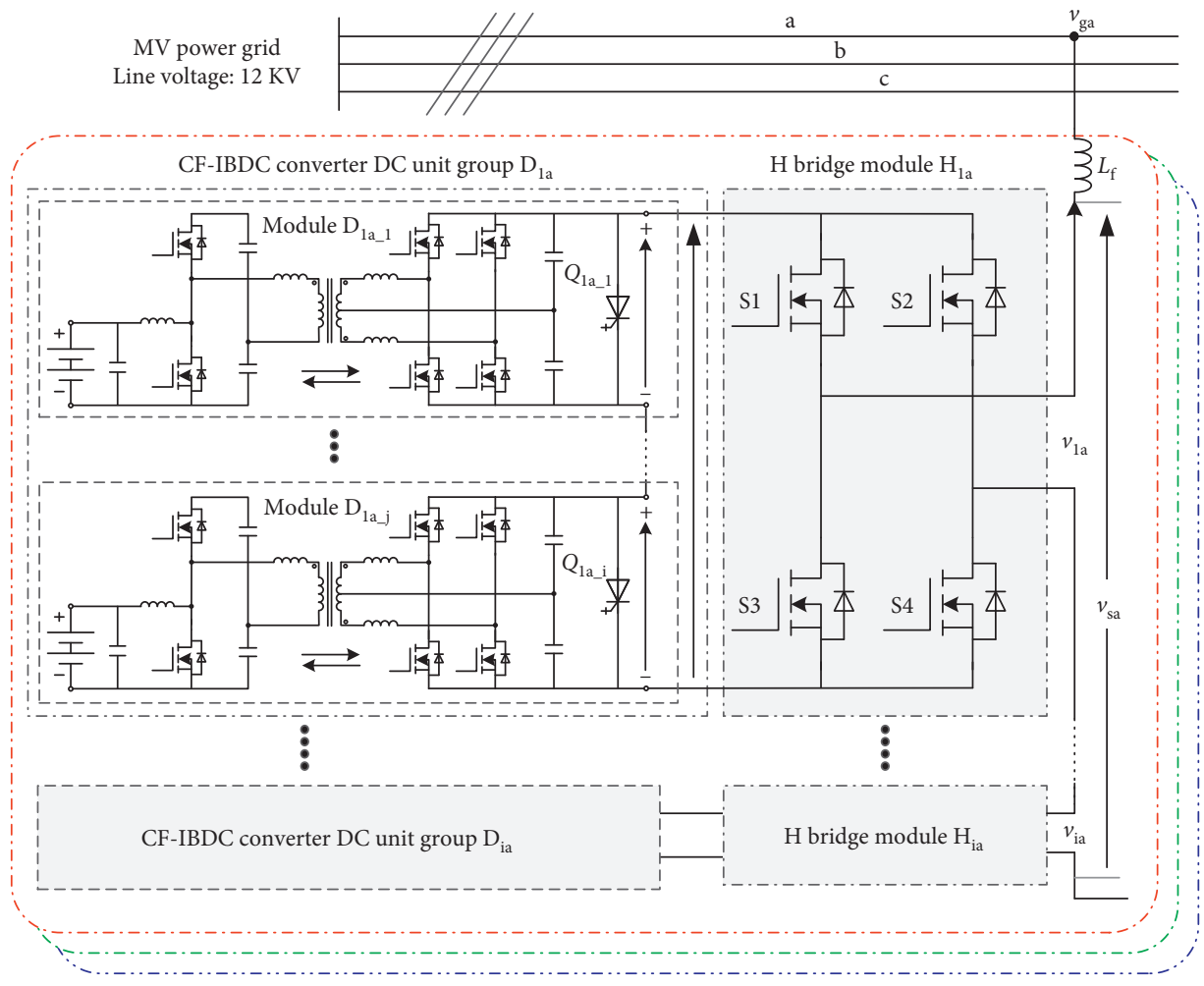

FIGURE 1: Grid-connected system of RBES based on CPET.

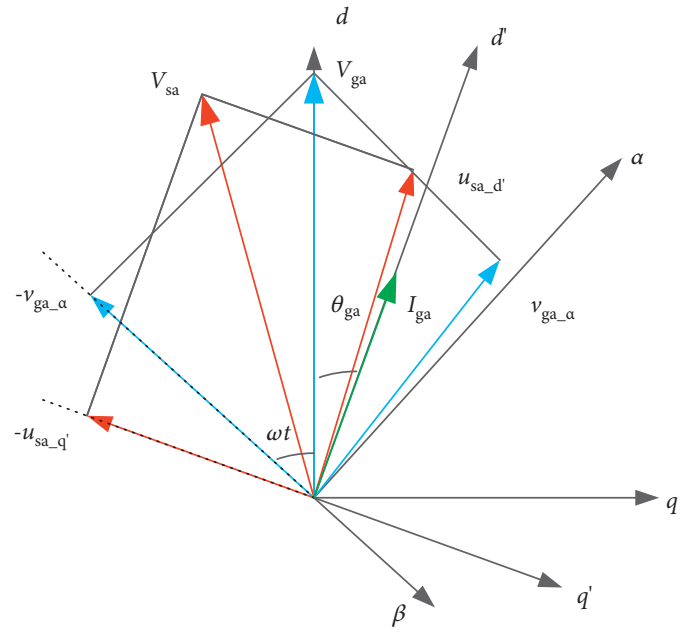

(a)

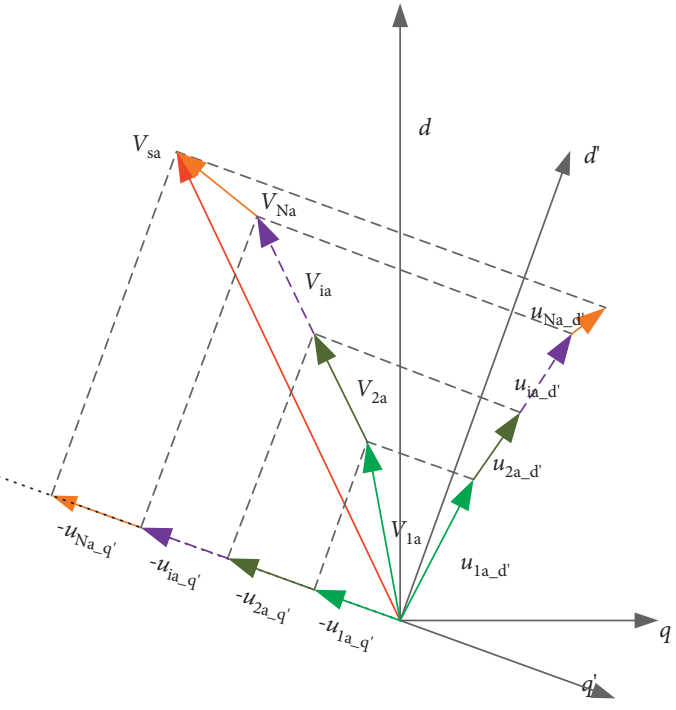

(b)

Figure 2: The relationship between the $\alpha-\beta$ coordinate system, the $d-q$ coordinate system, and the $d^{\prime}-q^{\prime}$ coordinate system. (a) The relationship between phase A grid voltage $V_{\text {ga }}$, grid current $I_{\text {ga }}$, and inverter output voltage $V_{\text {sa. }}$ (b) H-bridge inverter output voltage distribution.

A vector diagram of the $\mathrm{AC}$ voltage is given in Figure 2(a) to illustrate the power distribution principle between the CHB modules of phase A. The same analytical method can be applied to phase B and phase C. The $d^{\prime}-q^{\prime}$ coordinate system is constructed in the vector diagram, where the $d^{\prime}$ axis is in phase with the grid current, and the $q^{\prime}$ axis lags the $d^{\prime}$ axis by $90^{\circ}$. Obviously, the $d^{\prime}$ axis component of the inverter output voltage $V_{\text {sa_d }}$ determines the active power, while the $q^{\prime}$ axis component $V_{\text {sa } q^{\prime}}$ determines the reactive power. In Figure 2(b), the power distribution of $\mathrm{CHB}$ topology in different grid-connected power situations is described. The grid-connected voltage $V_{\mathrm{sa}}$ output by $\mathrm{CHB}$ is synthesized from the output voltage $V_{\text {ia }}(i=1, \ldots, N)$ of $\mathrm{H}$-bridge modules with different amplitude and angle and 
$V_{\mathrm{ia} \_d^{\prime}}$ and $V_{\mathrm{ia} \_q^{\prime}}$ can be decoupled to realize independent control of active power and reactive power of each $\mathrm{H}$-bridge module. In the coordinate transformation of $d-q$ coordinate system and $d^{\prime}-q^{\prime}$ coordinate system, the grid voltage and current reference angle $\theta_{\text {ga }}$ are the key to the transformation. The grid current $i_{\mathrm{ga}}$ can be measured and projected onto the coordinate system to obtain $i_{\text {ga } \_\alpha}$ and $i_{\text {ga } \beta}$. The grid current flowing through $\alpha \beta-d q$ coordinate system is transformed into the $d q$ coordinate system as follows:

$$
\left[\begin{array}{c}
i_{\mathrm{ga}_{-} d} \\
i_{\mathrm{ga} \_}
\end{array}\right]=\left[\begin{array}{cc}
\sin (\omega t) & -\cos (\omega t) \\
\cos (\omega t) & \sin (\omega t)
\end{array}\right]\left[\begin{array}{c}
i_{\mathrm{ga}_{-} \alpha} \\
i_{\mathrm{ga} \_} \beta
\end{array}\right] .
$$

Therefore, the reference angle of $\theta_{\text {ga }}$ of grid voltage and current can be obtained:

$$
\theta_{\mathrm{ga}}=\operatorname{tg}^{-1}\left(\frac{i_{\mathrm{sa} \_d}}{i_{\mathrm{sa}_{-} q}}\right)
$$

We substitute the result obtained from (4) into $d q-d^{\prime} q^{\prime}$ :

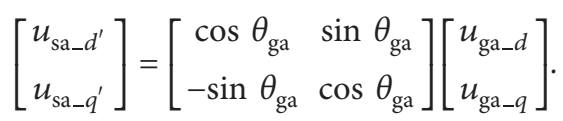

The voltage component based on $d^{\prime} q^{\prime}$ coordinate system can be obtained by (5), the voltage signals $u_{\text {sa }-d^{\prime}}$ and $u_{\text {sa } \_q^{\prime}}$ of active power and reactive power output are distributed to each $\mathrm{H}$-bridge module through the energy balance control algorithm, and then the $d^{\prime}$ axis voltage reference value of each H-bridge module can be obtained, so as to control the active power component of corresponding module, and the obtained $q^{\prime}$ axis voltage reference value controls the reactive power component. In order to convert the voltage component of the $d^{\prime} q^{\prime}$ coordinate system into the modulation ratio control quantity of each module of the $\mathrm{CHB}$ topology, we transform the output voltage reference signal of the active power and reactive power of the $d^{\prime} q^{\prime}$ coordinate system obtained by the equalization control to the $\alpha \beta$ coordinate system through the $d^{\prime} q^{\prime}-\alpha \beta$ coordinate system:

$$
\left[\begin{array}{c}
u_{\mathrm{ia} \_\alpha}^{*} \\
u_{\mathrm{ia} \_\beta}^{*}
\end{array}\right]=\left[\begin{array}{cc}
\sin \left(\omega t+\theta_{\mathrm{ga}}\right) & \cos \left(\omega t+\theta_{\mathrm{ga}}\right) \\
-\cos \left(\omega t+\theta_{\mathrm{ga}}\right) & \sin \left(\omega t+\theta_{\mathrm{ga}}\right)
\end{array}\right]\left[\begin{array}{c}
u_{\mathrm{ia} \_d}^{*} \\
u_{\mathrm{ia} \_q}^{*}
\end{array}\right] .
$$

As shown in Figure 2(a), the output reference signals of each module are $u_{\mathrm{ia}}^{*}=u_{\mathrm{ia} \_}^{*}$, the modulation ratio of each H-bridge module can be calculated: $m_{\mathrm{ia}}^{*}=u_{\mathrm{ia}}^{*} / V_{\mathrm{dcia}}$. Then, the decoupling control of active power and reactive power can be completed, and the power balance control of each $\mathrm{H}$-bridge module can be realized easily. In the control, the modulation ratio should not exceed the modulation ratio control limit to avoid output instability. This paper does not analyze the overmodulation control.

2.3. Cascading CF-IBDCAnalysis. The structure of CF-IBDC is shown in Figure 3. The low-voltage side of the converter is a multiplexed half-bridge structure. The low-voltage halfbridge and the input inductor $L_{\mathrm{b}}$ constitute the front Buck/ Boost circuit to obtain the capability of wide input voltage range. The input inductance makes the converter have current source characteristics to reduce the input current ripple. At the same time, the half-bridges and capacitorbridges in both primary and secondary sides constitute the dual active bridge. The capacitor arm clamping the voltage of switching tube can solve the problem of high voltage spike. The center tap on the high voltage side of the transformer yields two high voltage half-bridge structures, and interbridge circulation can solve the soft switch problem under light load and improve the efficiency in the full power range.

\section{Analysis of Hierarchical Control Strategy}

The CPET based RBES grid-connected system designed in this paper mainly realizes the control target of smooth power fluctuation and peak cut of renewable energy. The system is divided into 2-layer structure, composed of DC-DC part and DC-AC part, which can realize the independent control of the two parts. Combined with the grid-connected RBES topology, the control requirements and objectives of the energy storage system are decomposed, and the three-layer control structure of the RBES system with CPET structure is designed to achieve their respective control objectives, namely, the energy layer, the power layer, and the SOC layer.

In the RBES grid-connected system, the DC-DC stage is divided into charging state and discharging state, and the DC-AC stage is divided into inverting state and rectifying state. When the RBES grid-connected system works in the inverter state, the repurposed battery discharges and the energy is transmitted forward. The whole system is powered by the repurposed battery to the grid. When the RBES gridconnected system works in the rectifier state, the repurposed battery is charged and the energy is transmitted in reverse, and the whole system absorbs the excess energy from the grid side to the repurposed battery.

Whether the energy is transmitted forward or backward, the control objectives of the DC-AC stage are grid-connected current tracking of the grid voltage and the completion of active and reactive power scheduling instructions, while the control objectives of the DC-DC stage are to stabilize the voltage of the HVDC bus and balance the charged state of repurposed batteries.

The DC-DC stage and the DC-AC stage are connected by the HVDC bus. The voltage of the HVDC bus $V_{\text {dcik }}$ will be affected by the two stages of the circuit. In the case of rectifier, the DC-AC stage raises the voltage of the DC bus, while in the case of inverter, the DC-AC stage pulls down the voltage of the DC bus. In this paper, the HVDC bus voltage is controlled by the DC/DC stage. Based on the above analysis, it can be known that the automatic switching between forward flow and reverse flow of energy can also be realized in the stable voltage control implementation of CF-IBDC converter; two-stage circuit control can also be completely decoupled which only focus on their respective control objectives. Hierarchical control strategy diagram is shown in Figure 4.

3.1. Energy Layer Control Strategy. According to the power output of renewable energy and the expected design value of system power at the current time of the power grid, the 


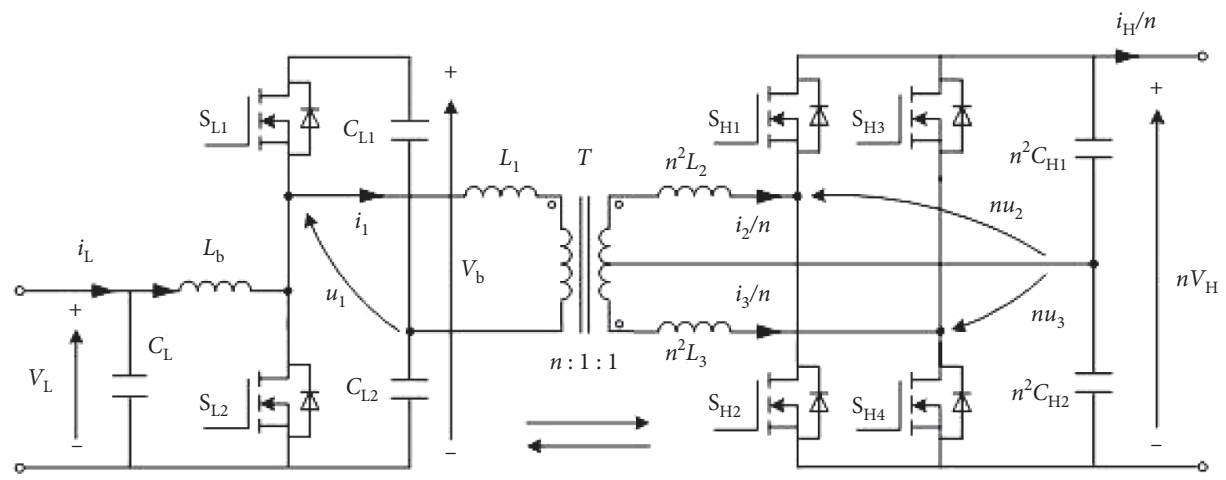

Figure 3: CF-IBDC topology.

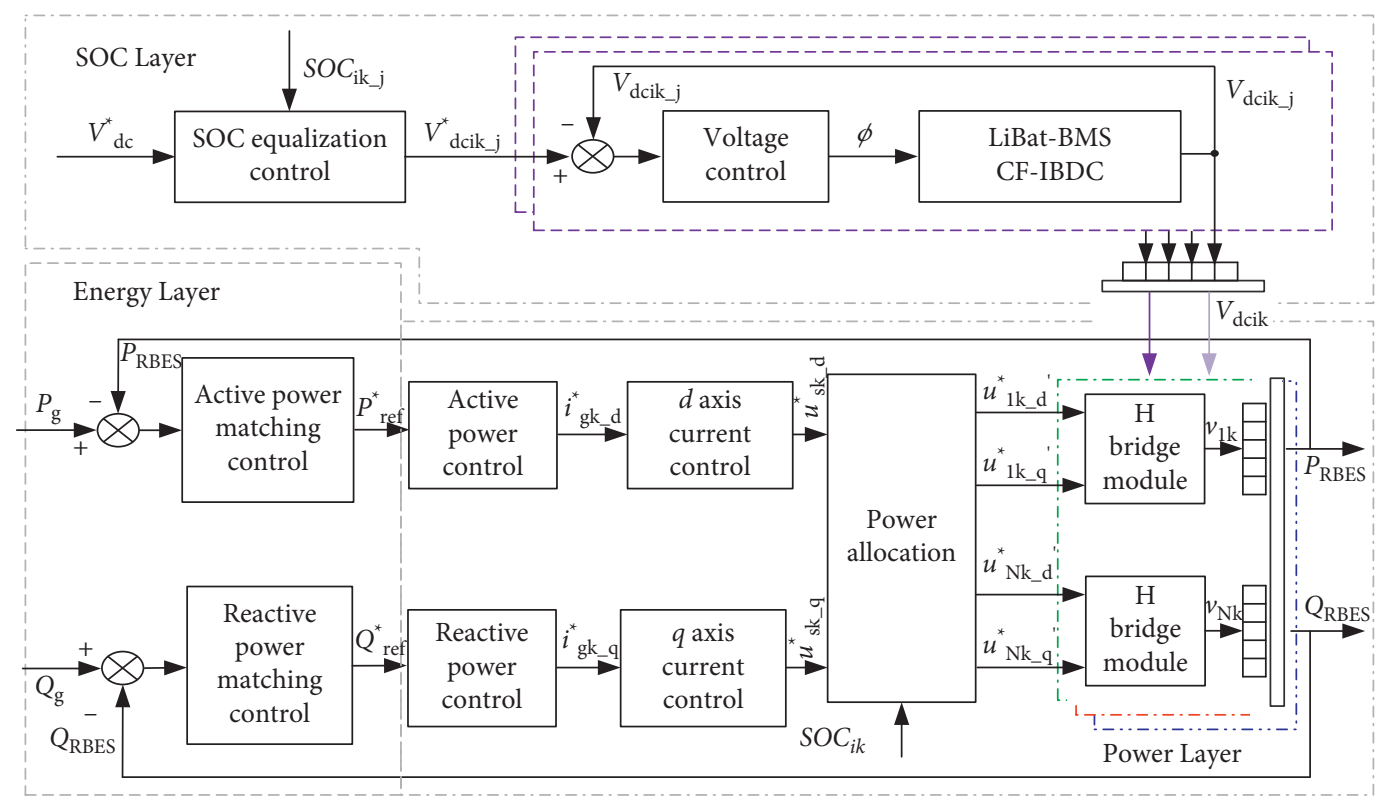

FIgURE 4: Block diagram of hierarchical control strategy.

power dispatching center obtains the active power dispatching instruction $P_{\mathrm{g}}$ and reactive power dispatching instruction $Q_{\mathrm{g}}$ and sends the dispatching instructions to the RBES grid-connected system. The RBES grid-connected system achieves the control target of energy layer according to the control strategy shown in Figure 5.

In the energy layer control, the RBES system detects the reactive power QRBES and active power PRBES of PCC nodes and takes them as a feedback value. The reactive power dispatch instruction $Q_{g}$ and the active power dispatch instruction $P_{\mathrm{g}}$ are, respectively, differentiated from the feedback value, getting the next cycle adjustment of power value $\Delta P$. Then, the power closed-loop control is completed to obtain the reference value of active power and the reference value of reactive power. By transferring the reference value to the power layer, the RBES grid-connected system based on CPET is controlled to realize the tracking control of scheduling instructions.

The energy layer regulates the dynamic response speed of the RBES grid-connected system, controls the start-stop and power switching of the system, which realizes the nonimpact and flexible switching of operating conditions, and controls the active power and reactive power output of the RBES system to reach the grid dispatching value.

3.2. Power Layer Control Strategy. The control objective of $\mathrm{CHB}$ topology is to track the active power of the energy layer by referring to the given value $P^{*}$ ref and the reactive power by referring to the given value $Q^{*}$ ref, which realizes the dispatching instruction of the grid dispatching center. The gridconnected current tracks the voltage on the side of the grid which is the standard sine wave. The control strategy of the power layer is shown in Figure 5.

The above energy layer control strategy calculates the given values of active power and reactive power and transfers the reference values to the power layer. Firstly, according to (7), the power layer control obtains the given reference quantity of $d$ axis current and the given reference quantity of $q$ axis current. The active and reactive power value of the 
RBES grid-connected system is evenly divided into the three-phase system. According to single-phase PLL $d q$ vector transformation technology, the voltage current detection signal of the system is obtained by $a b c / d q$ vector transformation in the $d q$ static coordinate system, and the active power and reactive power are decoupled-controlled in the static coordinate system. The system error signal is obtained by the difference between the given reference value of $d q$ axis current and the actual current flow, which is calculated by PI controller to obtain the voltage signals of $d$ axis and $q$ axis:

$$
\left\{\begin{array}{l}
i_{\mathrm{gk} \_d}^{*}=\frac{P_{\mathrm{ref}}^{*}}{3 v_{\mathrm{gk} \_d}}, \\
i_{\mathrm{gk} \_q}^{*}=\frac{Q_{\mathrm{ref}}^{*}}{3 v_{\mathrm{gk} \_d}} .
\end{array}\right.
$$

The voltage signal of $d q$ axis and the charged state $\mathrm{SOC}_{\mathrm{ik}}$ value of each DC unit group are input into the power distribution module, respectively. According to the active power and reactive power distribution (8), the voltage given signal of $d q$ axis of each module can be obtained. Although the active power according to $\mathrm{SOC}_{\mathrm{ik}}$ value distribution can inhibit DC unit charged state significantly difference between groups and avoid the short board effect, it actually cannot completely eliminate the differences of DC units charged state between groups. Considering the capacity and control complexity of system, the small difference of charged state in engineering application is acceptable, so the control strategy of allocating active power according to the charged state of each DC unit group is feasible. The reactive power is an equilibrium control, and each $\mathrm{H}$-bridge module has the same parameters and reactive power capacity, which makes the reactive power divided equally among all $\mathrm{H}$-bridge units:

$$
\left\{\begin{array}{l}
u_{\mathrm{ik} \_d}^{*}=\frac{u_{\mathrm{sk} \_d}^{*} \cdot \mathrm{SOC}_{\mathrm{ik}}}{\sum_{i=1}^{N} \mathrm{SOC}_{\mathrm{ik}}}, \\
u_{\mathrm{ik} \_q}^{*}=\frac{u_{\mathrm{sk} \_q}^{*}}{N} .
\end{array}\right.
$$

The modulation ratio of each module is different, which makes the RMS value of output AC voltage inconsistent, while the link structure makes the RMS value of each module the same, so each module has different power output value, which indirectly realizes the SOC value equalization control, and controls the total power of the cascade module and the change of the scheduling value of the system.

3.3. SOC Layer Control Strategy. In the SOC layer, the charging and discharging power of each module is evenly controlled according to the SOC status of the repurposed battery, which enables the balanced control of the SOC value of the repurposed battery to ensure the safe and stable operation of the battery pack. Combined with the working principle of the CF-IBDC converter, it can be seen that the power transmission direction is controlled by the phase shift angle between bridges, while the energy flow direction is automatically switched under the voltage stabilization control of the HVDC bus. Since the cascaded structure of each module makes the module have the same current, it is necessary to control different output voltage to regulate the output power of each module, so SOC equalization is to control the output voltage value of each module.

In Figure 6, voltage loop is used in CF-IBDC to realize the output voltage control, the control parameter is the phase shift angle $\phi$ between bridges, and voltage matching is achieved by controlling duty cycle $D$, which can reduce converter loss. SOC equalization control strategy requires that different voltage values of each module be given, respectively, and output power be adjusted to realize SOC equalization. The voltage error signal can be obtained by making the difference between the voltage given value and voltage sampling $V_{\mathrm{H}}$. The phase shift angle can be obtained by PI regulator. The PWM driving signal can be generated by the phase shift square wave controller, and then the voltage stabilizing control can be completed by adjusting the CFIBDC.

The voltage distribution controller is shown in Figure 7, the difference between the average $\mathrm{SOC}_{\mathrm{ik}}$ value of the DC unit group and the state of charge value of each module to obtain the error signal of the SOC value, which is corrected by the PI controller for the corresponding module voltage. In the SOC equalization control, a correction coefficient calculator is designed to distinguish the different equilibrium objectives of different SOC based on charge and discharge, which is actually a hysteresis control strategy. We multiply the obtained voltage correction value and correction coefficient to obtain the SOC equalization correction voltage increment and then add the given value of the mean voltage and the SOC equalization correction voltage increment to obtain the given value of the voltage of each module. The corresponding last module compensates the voltage regulator value of the whole DC unit group; that is, it satisfies equation (9) and controls the whole DC unit group by the voltage given value of the module- $M$, which realizes the voltage regulator control of the HVDC bus:

$$
V_{\text {dcik_M }}^{*}=V_{\text {dcik }}^{*}-\sum_{j=1}^{M-1} \Delta V_{\text {dcik_j}_{\_} .}^{\prime}
$$

The correction factor calculator is shown in Figure 8. In the process of voltage rise, when the voltage of HVDC bus reaches $3050 \mathrm{~V}$, the system enters the charging control area and the correction coefficient gradually increases to 1 . When it is higher than $3100 \mathrm{~V}$, the correction coefficient remains at 1 . In the process of voltage reduction, when the voltage is reduced to $2950 \mathrm{~V}$, the correction factor gradually decreases to -1 and maintains -1 after $2900 \mathrm{~V}$. The voltage of the HVDC bus ranges from $2950 \mathrm{~V}$ to 


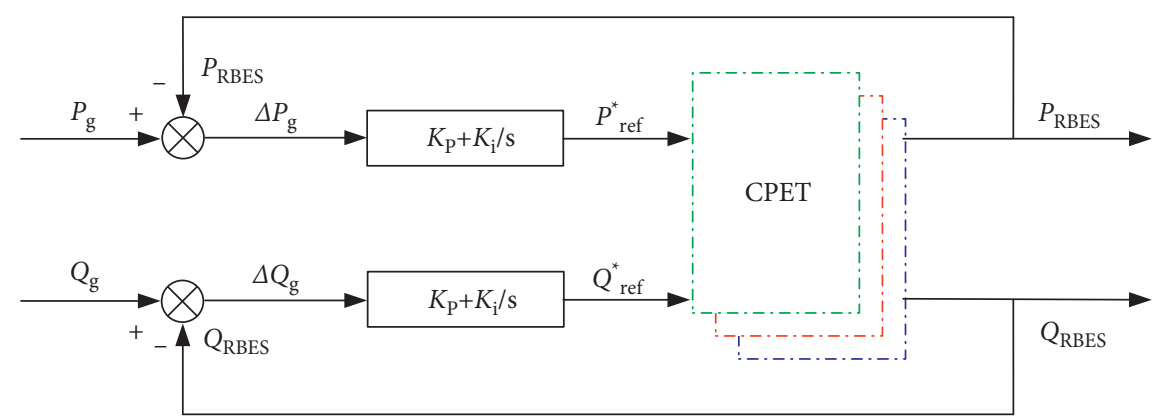

(a)

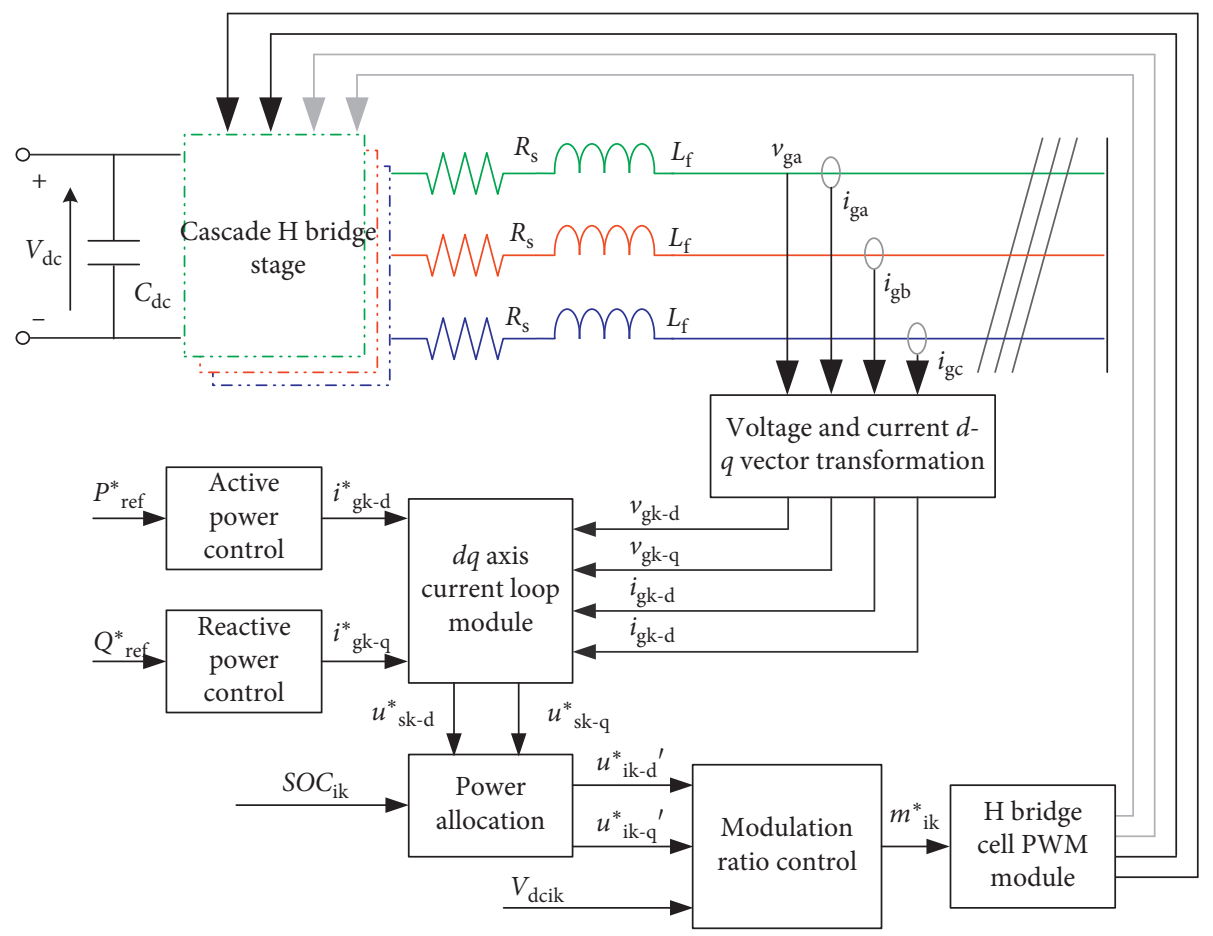

(b)

FIgURE 5: Power layer control strategy block diagram.

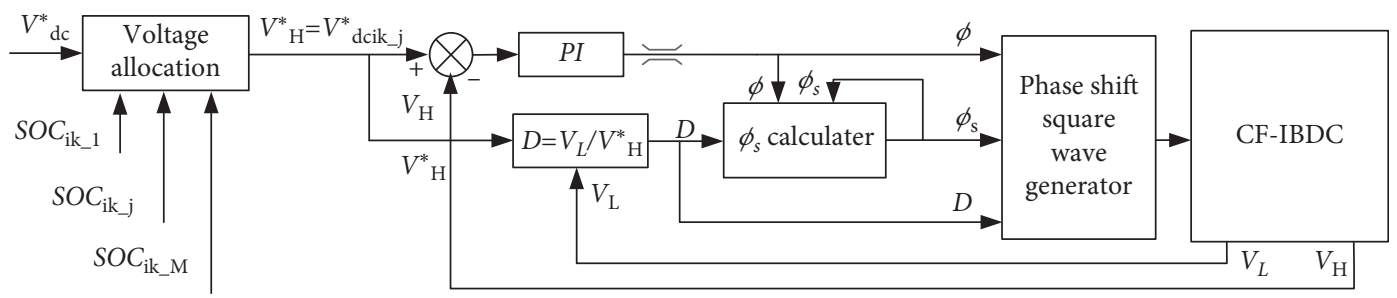

FIGURE 6: SOC layer control strategy block diagram.

$3050 \mathrm{~V}$, which is the hysteresis area controlled by the system. In other words, the voltage of the HVDC bus will fluctuate in the voltage hysteresis area and stabilize at a certain voltage value.

\section{Simulation Results}

In order to verify the effectiveness of the CPET topology and its control strategy involved in this paper, a simulation model of the RBES system was built by Matlab software. The parameters used in the simulation are shown in Table 1.

In the power layer simulation, the variation of power scheduling value is shown in Figure 9. The whole schedule consists of six steady-state operating points and dynamic processes between them, which can reflect different operating conditions of the system, respectively. As can be seen in this figure, the grid voltage $V_{\text {ga }}$ of phase A is taken as the reference signal, the three-phase grid current can ensure tracking the grid 


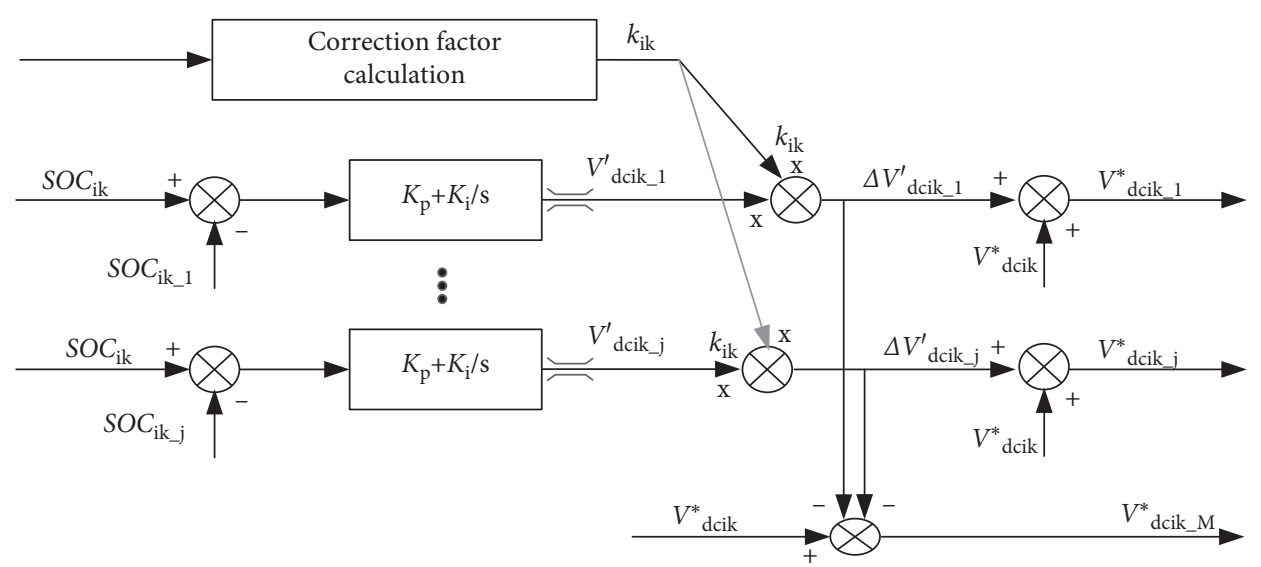

FIGURE 7: SOC equalization control strategy.

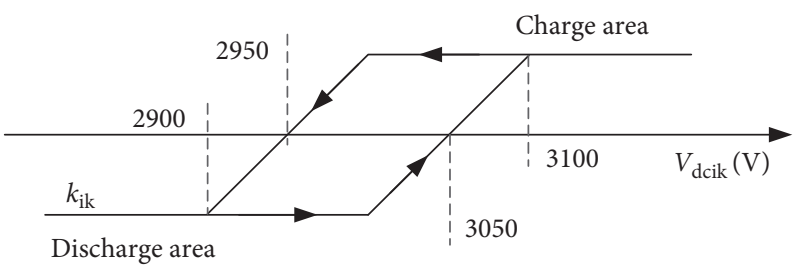

FIGURE 8: Hysteresis control strategy for charge and discharge switching.

voltage as a standard sine wave after the change of active and reactive power, and the RBES system can output the dispatching power value with no difference. In the start-up and power switching state of the RBES system, the impact of the power grid is small, and the scheduling instructions can be quickly tracked and adjusted in a short time to meet the engineering requirements of the large-capacity system. In reactive or active scheduling instruction switching, the two can reach a stable state without mutual influence.

Figure 10 shows the modulation waveforms and the output voltage waveforms of each module when the DC unit group has different SOC values. In the simulation setting, the power of the energy storage system is $1.5 \mathrm{MW} / 1.5 \mathrm{MVar}$, and the SOC values of the DC unit group are $0.7,0.7,0.8$, and 0.75 in turn.

It can be seen that each modulated wave has the same phase but different amplitude. In the detail figure, SOC values of $\mathrm{H}_{1 \mathrm{a}}$ module and $\mathrm{H}_{2 \mathrm{a}}$ module are the same, and the modulation wave is the same; the $\mathrm{SOC}$ value of $\mathrm{H}_{3 \mathrm{a}}$ module and $\mathrm{H}_{4 \mathrm{a}}$ module are both larger than that of $\mathrm{H}_{1 \mathrm{a}}$ module, so it can be seen that the amplitude of modulation is greater than that of $\mathrm{H}_{1 \mathrm{a}}$ module, and the difference of amplitude of modulation is equal. The corresponding output waveforms of each module are $\pm 3 \mathrm{kV}$ and $0 \mathrm{~V}$ level, while within a cycle, the phase shift between the drive signals of adjacent modules is $45^{\circ}$, and different modulation amplitude corresponds to the conduction time of different switching tube.

In the SOC layer simulation of the RBES system, the parameters of capacity and SOC value of repurposed lithium batteries within the DC unit group are shown in Table 2. The entire charging and discharging processes are simulated to verify the correctness of the SOC balancing strategy.
From the comparison and analysis of the SOC value in the charging and discharging simulation waveform diagrams in Figure 11, it can be seen that for repurposed lithium batteries with the same initial SOC value and actual capacity, the output voltage setting values of the corresponding modules are always the same (e.g., $\mathrm{Ei}_{\mathrm{k}_{\mathrm{k}} 1}$ and $\mathrm{Ei}_{\mathrm{k} \_2}$ ). For repurposed lithium batteries with equal initial SOC but different actual capacity, with the increase of discharge time, the difference of output voltage setting values of modules gradually increases, but the SOC values remain the same (e.g., $\mathrm{Ei}_{\mathrm{k}_{\_} 1}$ and $\mathrm{Ei}_{\mathrm{k} \_3}$ ). For repurposed lithium batteries with different initial SOC values and the same actual capacity, with the increase of discharge time, the output voltage setting values corresponding to the modules gradually tend to be consistent and finally equal, and the difference in SOC values also gradually decreases, tending to be consistent and finally equal (e.g., $\mathrm{Ei}_{\mathrm{k} \_1}$ and $\mathrm{Ei}_{\mathrm{k} \_4}$ ). Under different working conditions of the RBES system, the voltage of high-voltage bus can always maintain a steady state of $3 \mathrm{kV}$, which verifies the effectiveness of the control.

\section{Experimental Results}

In order to test the control algorithm, a single-phase RBES grid-connected experimental system with rated power of $1 \mathrm{~kW}$ was designed by referring to the parameter design and device selection method of the aforementioned $3 \mathrm{MVA} /$ $12 \mathrm{kV}$ system, so as to verify the correctness of the conclusions obtained from the above analysis. The experimental platform is designed as a single-phase AC $220 \mathrm{~V}$ grid-connected system, in which the number of cascaded $\mathrm{H}$-bridges is $N=2$, and the number of cascaded CF-IBDC is set as $M=2$. 
TABLE 1: Simulation model parameters.

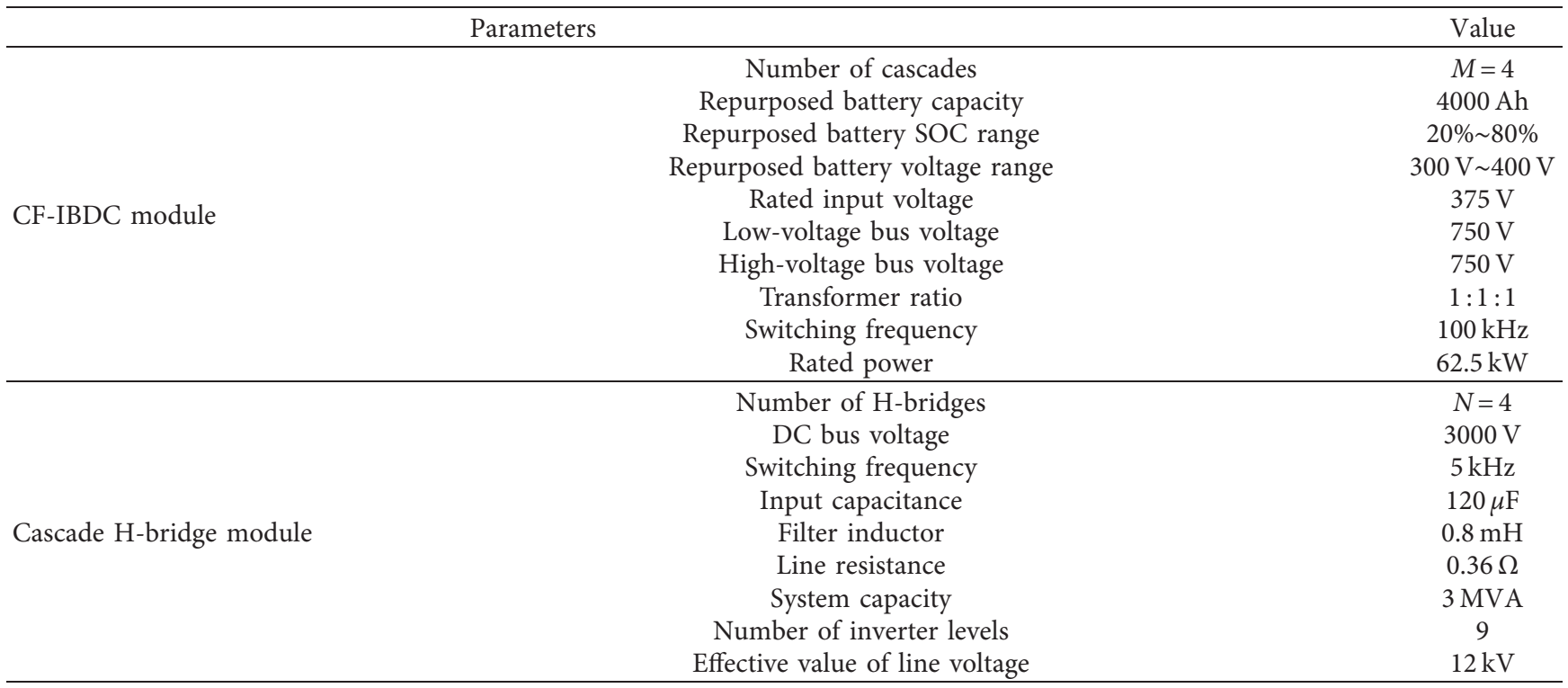
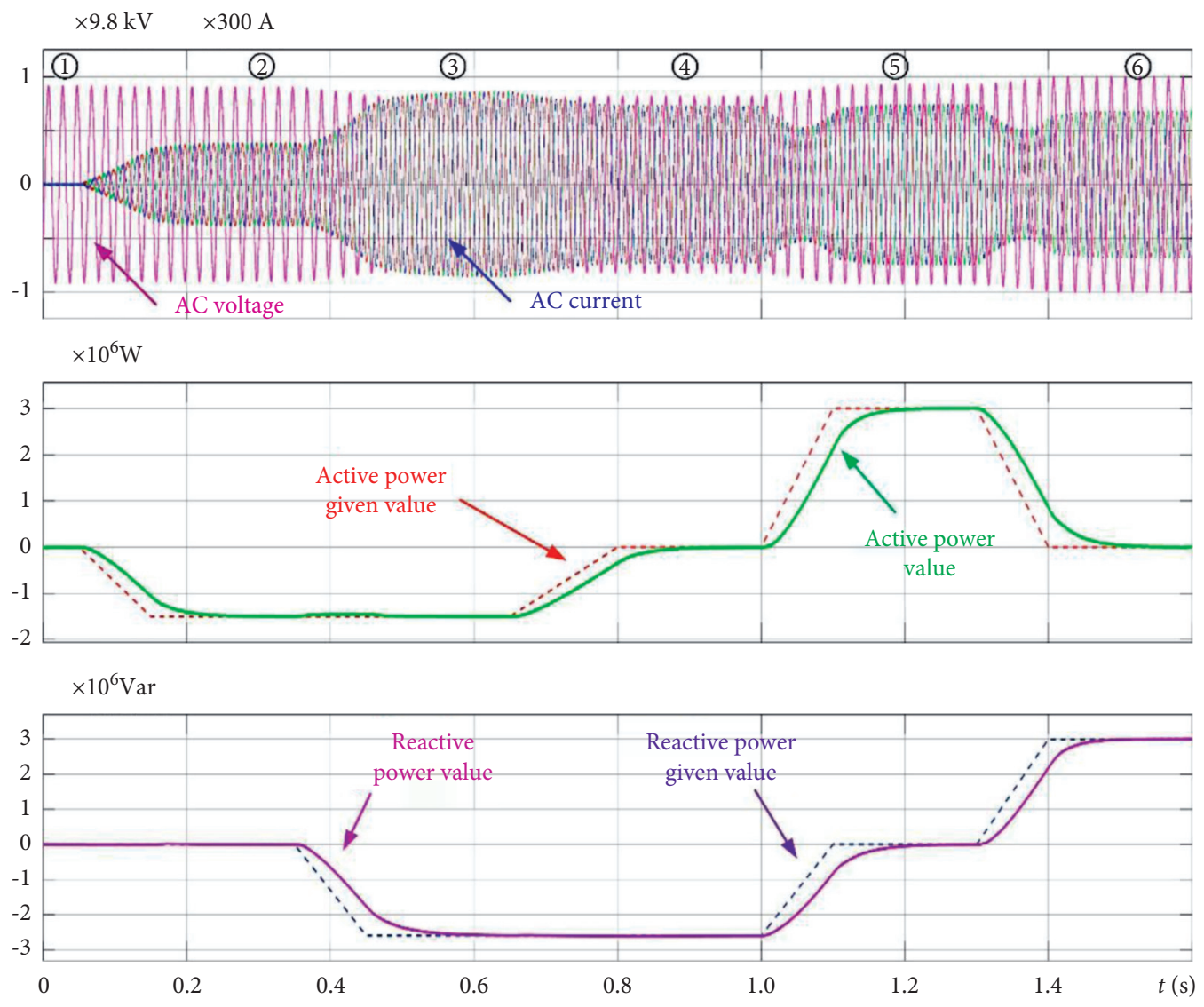

FIGURE 9: Simulation results of power layer energy forward and reverse flow.

The design of the experimental platform is shown in Figure 12.

The rated power of the single CF-IBDC converter is $250 \mathrm{~W}$, the rated input voltage is $50 \mathrm{~V}$, the output voltage is controlled at $100 \mathrm{~V}$, and the two modules cascade to obtain $200 \mathrm{~V}$. The rated power of a single $\mathrm{H}$-bridge module is
$500 \mathrm{~W}$, the rated input voltage is $200 \mathrm{~V}$, and the detailed parameters of the CF-IBDC converter and CHB topology are shown in Table 3.

Figure 13 shows the experimental platform diagram of the DC unit group. In the experiment, two DC stabilized power supplies are connected to the CF-IBDC converter 

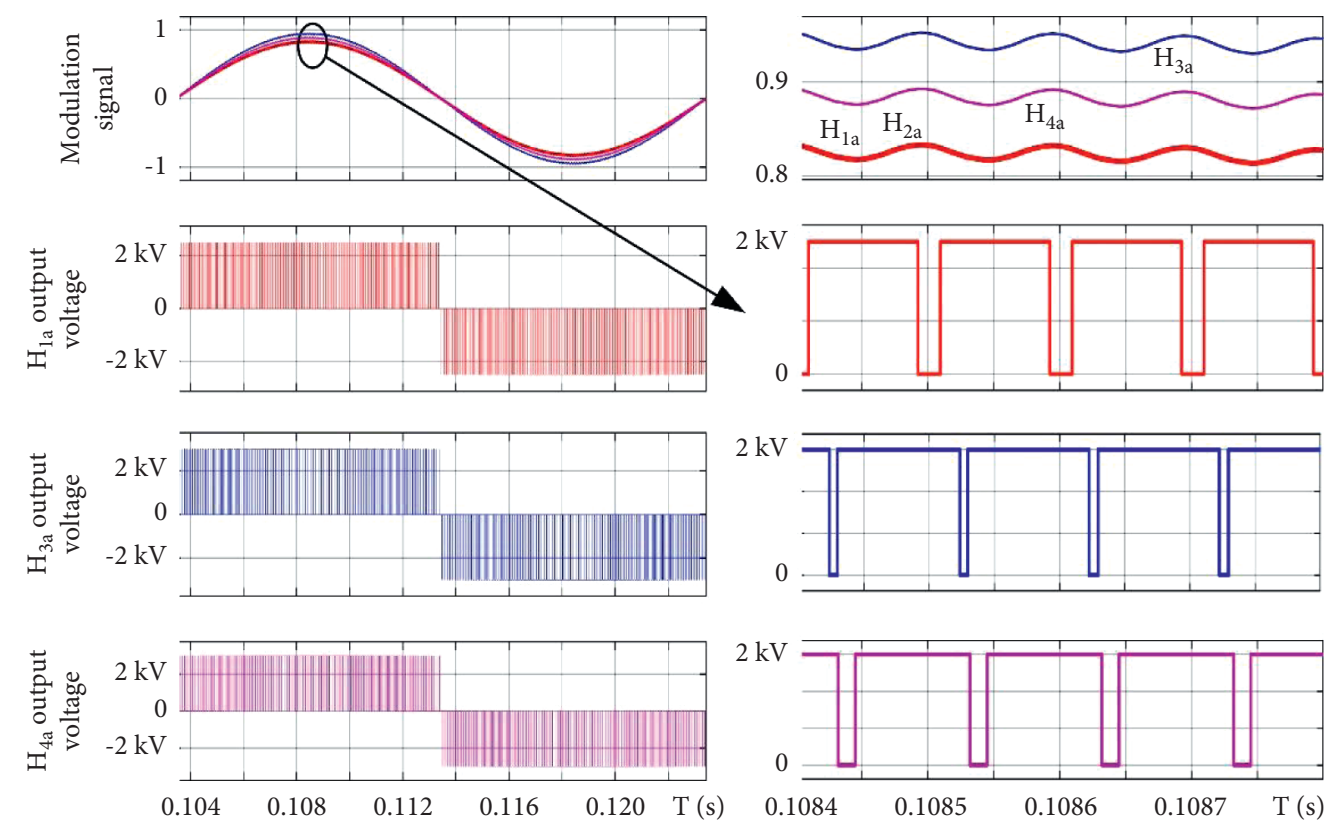

FIgURE 10: Modulation waves and module output voltage waveforms of different SOC values of DC unit group.

TABLE 2: Simulation parameters of repurposed lithium batteries in charge and discharge states.

\begin{tabular}{lcccc}
\hline Repurposed lithium battery modules & $\mathrm{Ei}_{\mathrm{k} \_1}$ & $\mathrm{Ei}_{\mathrm{k} \_2}$ & $\mathrm{Ei}_{\mathrm{k} \_3}$ & $85 \%$ \\
\hline Actual capacity percentage & $90 \%$ & $90 \%$ & $\mathrm{Ei}_{\mathrm{k} \_4}$ \\
Initial SOC values & 0.2 & 0.2 & 0.2 & 0.25 \\
\hline
\end{tabular}

cascaded to form a DC unit group, and the $200 \mathrm{~V}$ voltage obtained by cascading is connected to $\mathrm{H}_{1 \mathrm{a}}$ module. The other $\mathrm{H}$-bridge module, $\mathrm{H}_{2 \mathrm{a}}$, is directly connected to $200 \mathrm{~V} \mathrm{DC}$ power supply. The experiment is mainly divided into two parts: one is the soft switching and voltage equalization analysis of the cascaded CF-IBDC unit and the second is the five-level grid-connected output waveform under the carrier phase shift of the cascaded H-bridge unit, which mainly includes the cascaded $\mathrm{H}$-bridge output voltage and current waveforms, active power, and reactive power compensation state waveforms.

Figure 14 shows the soft switching waveforms of the CFIBDC converter under the no-load condition. In the no-load state, the phase shift angle $\phi$ between the bridges is close to $0^{\circ}$, and the converter generates a circulating current through the phase shift angle $\phi_{\mathrm{s}}$ inside the bridge to achieve ZVS. Figure 15 shows the soft switching waveforms at half load. When the load reaches a certain condition, the output current can realize the soft switching of the high-voltage side switching tubes. In order to improve the overall efficiency of the converter, the SPS phase shift method is adopted. The phase angle $\phi_{s}$ is always 0 , and the converter can realize ZVS depending on the operating current.

Figure 16(a) shows the steady-state output waveforms at half load, the output voltage of each module has slight fluctuations, and the peak-to-peak output voltage is less than $5 \mathrm{~V}$, which meets the system requirements. The input voltage of the module $D_{1 a_{-} 1}$ is $45 \mathrm{~V}$ and the output voltage obtained by the equalization calculation is $95 \mathrm{~V}$. The input voltage of the module $D_{1 \mathrm{a} \_}$is $50 \mathrm{~V}$, and the output voltage obtained by the equalization calculation is $105 \mathrm{~V}$. The measured output voltage can be seen that the steady-state output voltage of module $D_{\mathrm{la}_{-} 1}$ is $95.1 \mathrm{~V}$, the steady-state output voltage of module $D_{1 \mathrm{a} \_} 2$ is $104 \mathrm{~V}$, the cascaded output voltage is $200 \mathrm{~V}$, and the output power is $250 \mathrm{~W}$.

Figure 16(b) shows the dynamic waveforms switching from half load to 3/4 load. The steady-state output voltage of module $D_{1 a_{-} 1}$ is $95.1 \mathrm{~V}$, the steady-state output voltage of module $D_{1 \mathrm{a} \_2}$ is $104 \mathrm{~V}$, and the steady-state cascaded output voltage is $200 \mathrm{~V}$. When the load is switched, the output voltage of the module $D_{1 \mathrm{a} \_2}$ fluctuates, which further affects the cascade output voltage, but the output gets the stability soon. It can be seen that the output voltage stabilizes before and after load switching of each module, which can realize different power output of each module under the premise of stable output voltage on the cascaded side.

Figure 17 shows the experimental waveforms when the output power of the $\mathrm{CHB}$ is $1.1 \mathrm{~kW}$, and the current waveform is in phase with the voltage waveform. The effective value of the voltage is $220 \mathrm{~V}$, the effective value of the current is $5 \mathrm{~A}$, the frequency of voltage and current is $50 \mathrm{~Hz}$, and the voltage and current waveforms are present. It is a standard sine wave with no phase difference. 

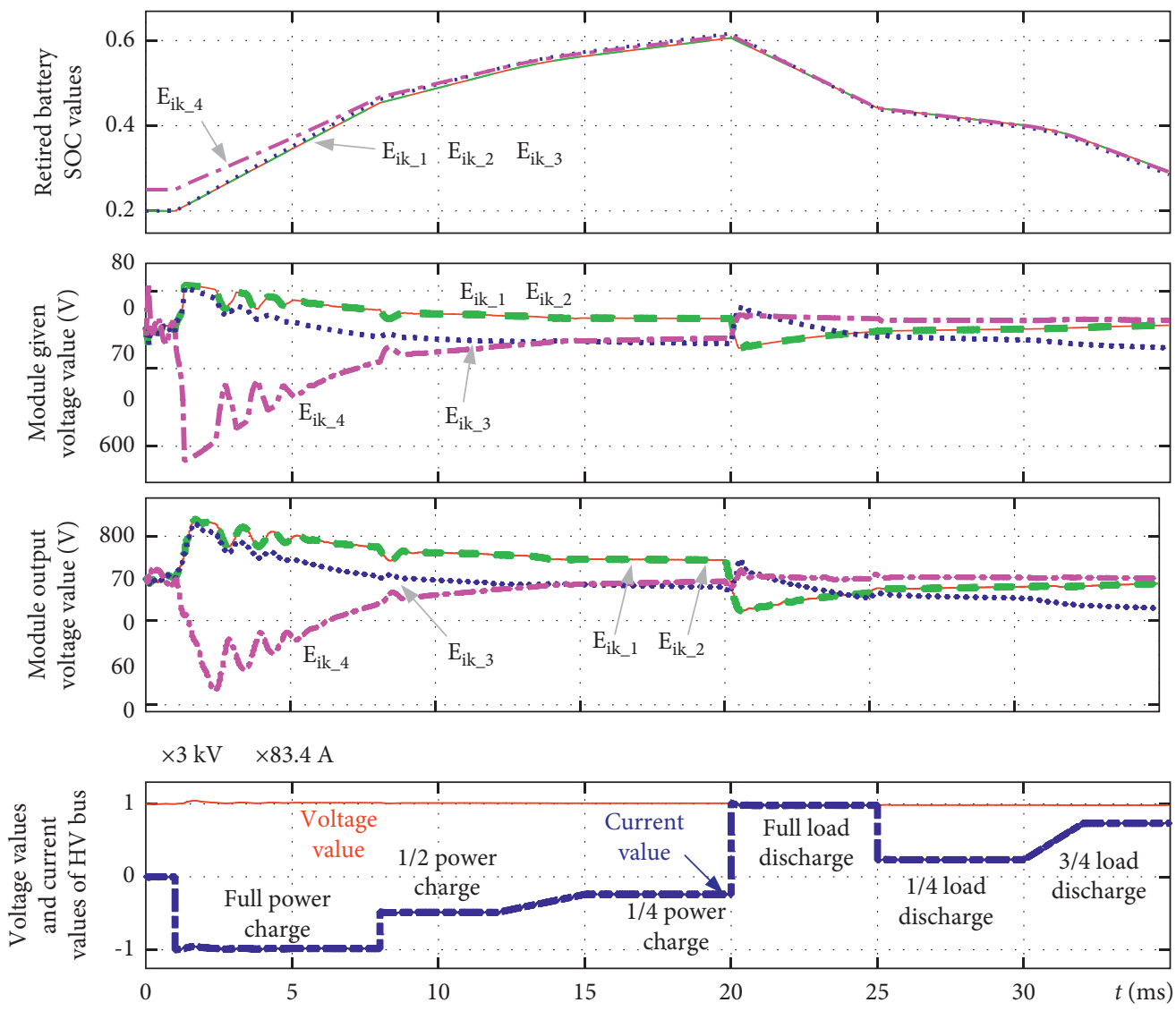

FIGURE 11: SOC layer charge and discharge simulation waveforms.

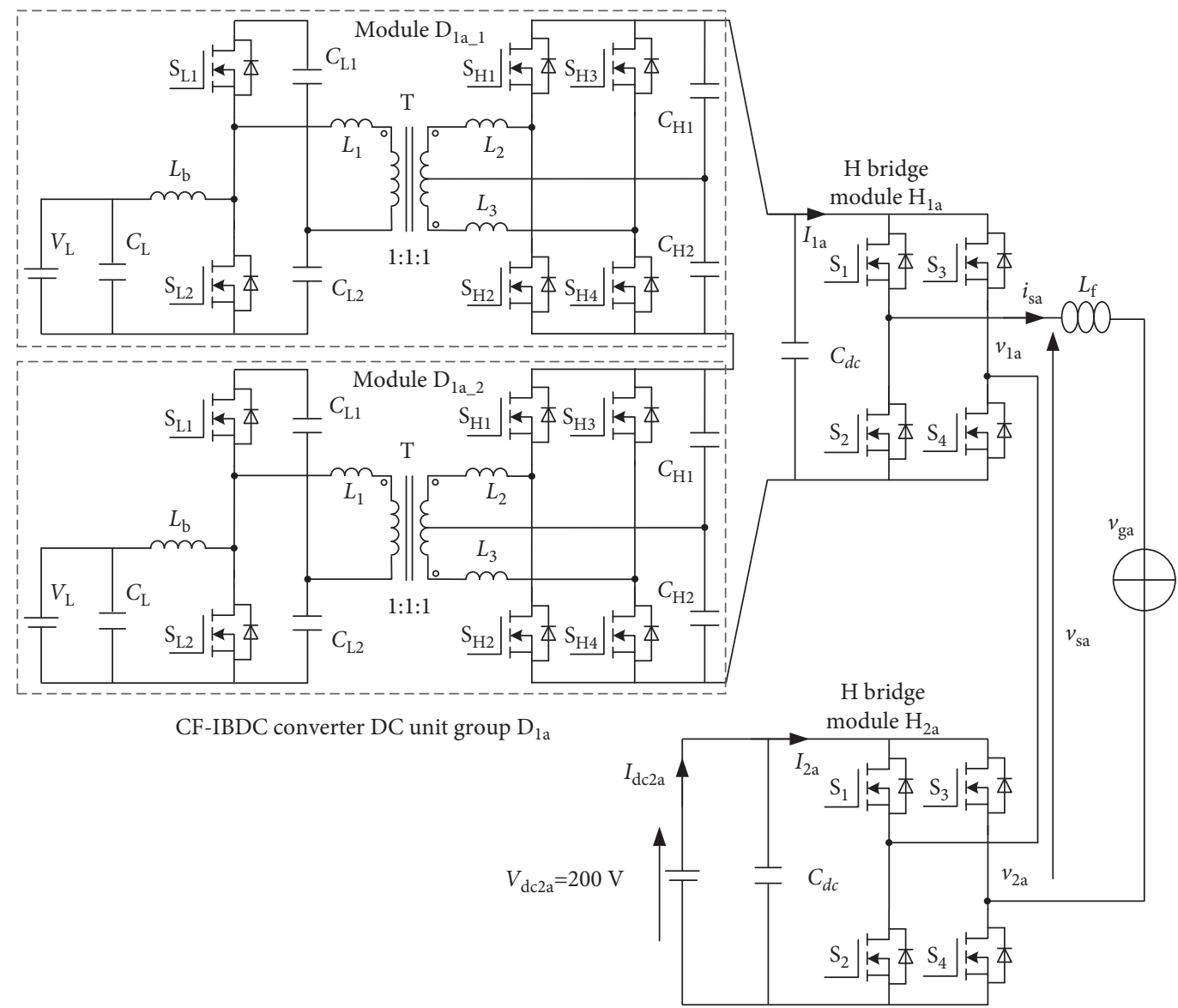

FIgURE 12: Experimental platform structure diagram. 
TABLE 3: Simulation model and experimental platform parameters.

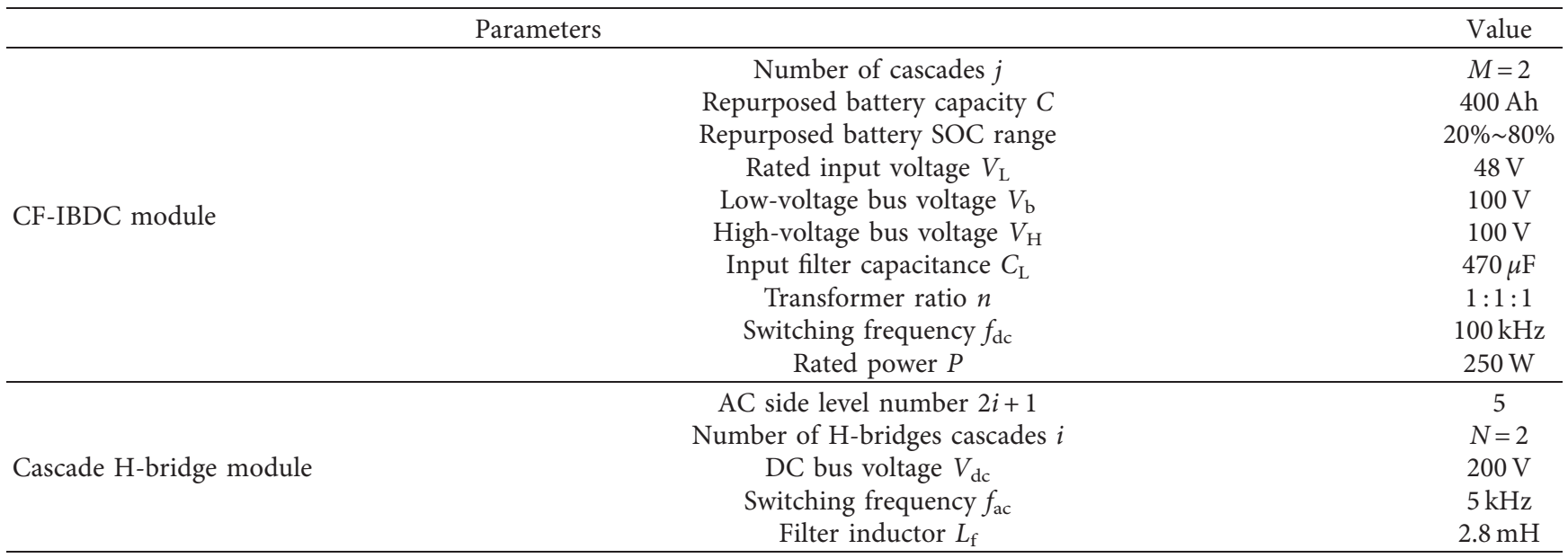

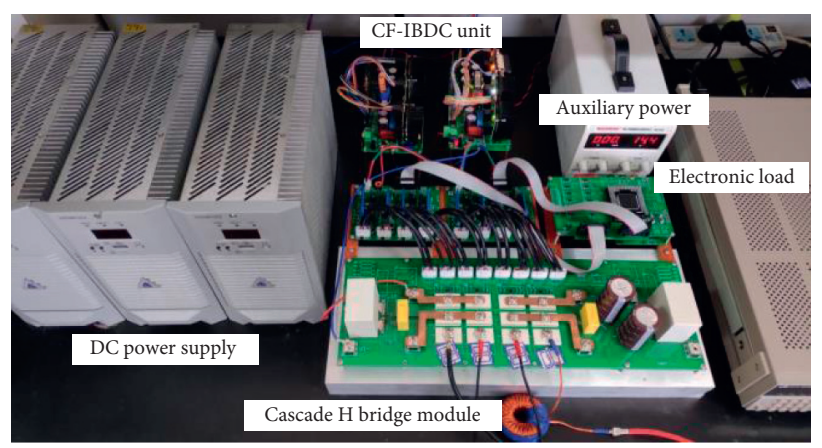

Figure 13: Experimental platform.

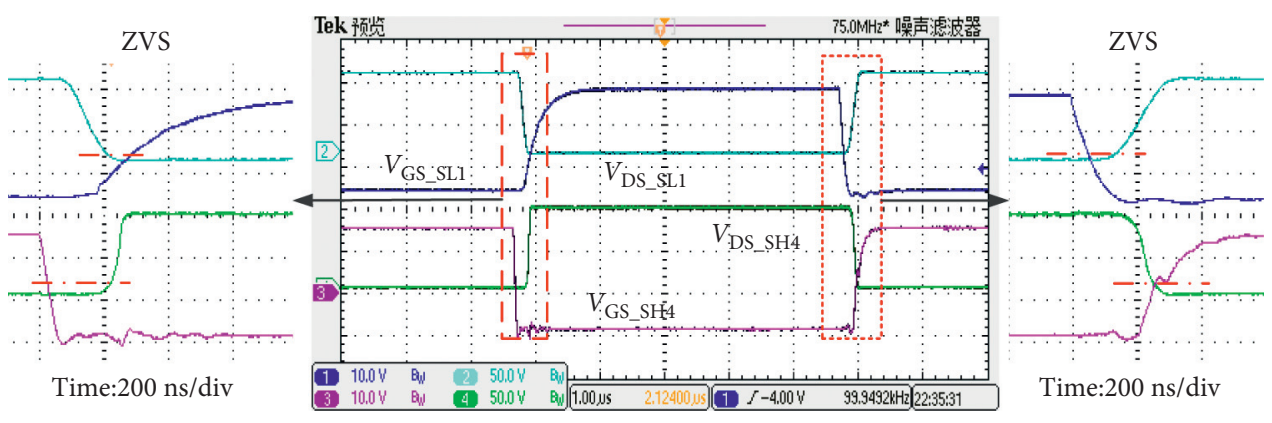

FIgURE 14: ZVS waveforms at no load.

Figure 18 shows the waveforms of the power switching. The CHB output voltage $v_{\text {sa }}$ is not affected by power switching. The AC current $i_{\text {ga }}$ has almost no distortion, and the voltage and current waveforms have no phase difference.
Figure 19 shows the waveforms of the off-grid operation with load and the grid-connected operation with resistive load. After grid-connected, the $\mathrm{CHB}$ converter delivers energy to both the off-grid load and the grid. 


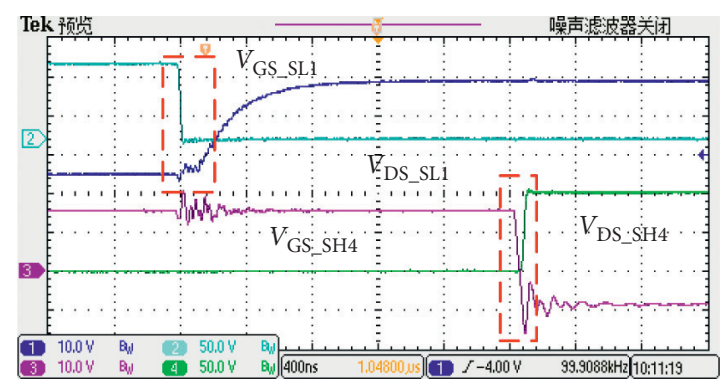

(a)

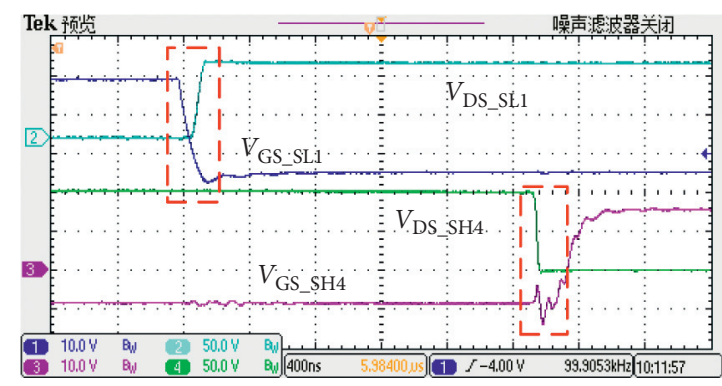

(b)

Figure 15: ZVS waveforms at half load.

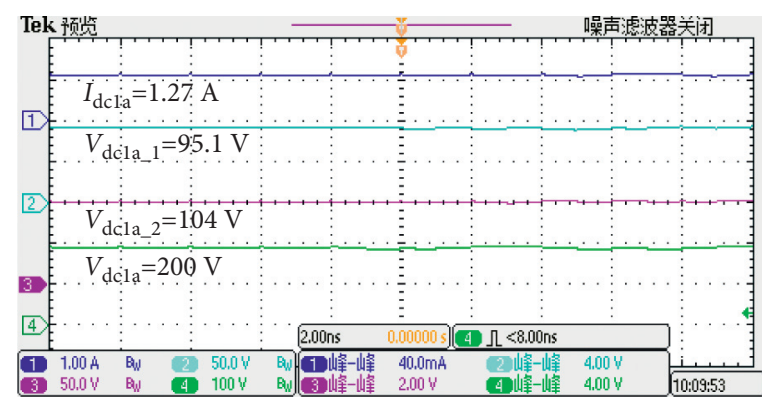

(a)

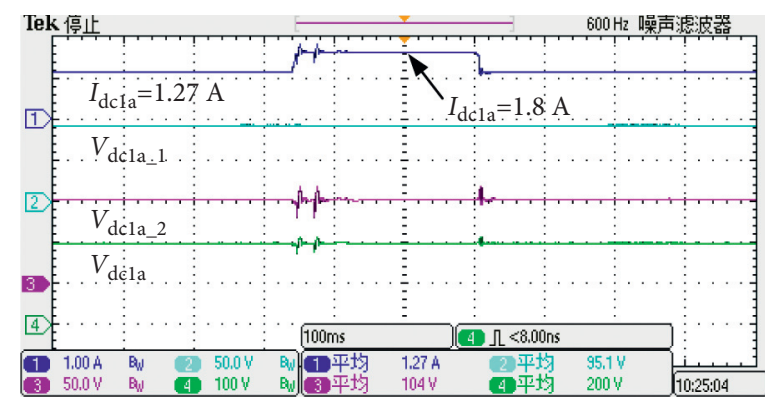

(b)

FIGURE 16: Steady-state output waveforms at half load: (a) steady state at half load and (b) dynamic.

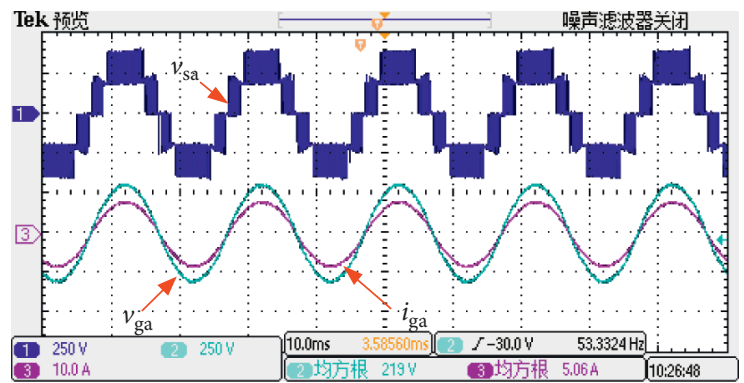

Figure 17: CHB steady-state operating waveforms.

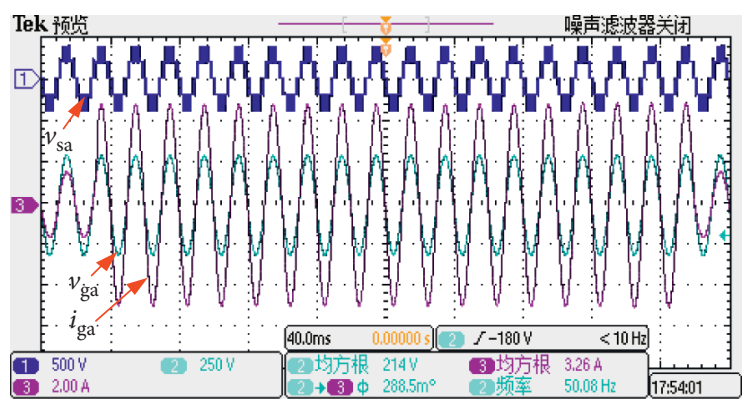

Figure 18: CHB dynamic operating waveforms. 


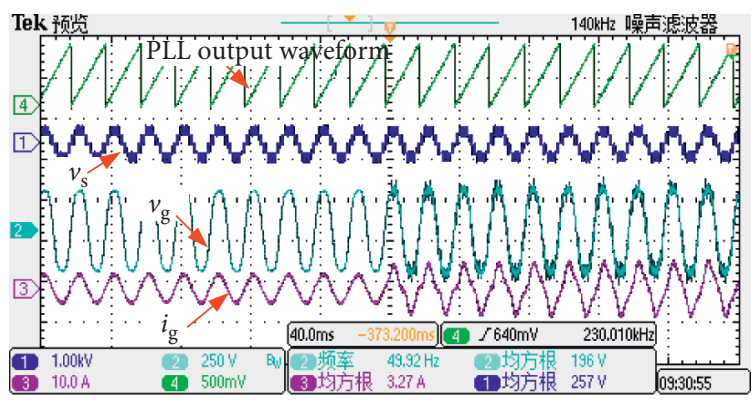

FIGURE 19: Off-grid operation to grid-connected operation waveforms.

By comparing the experimental waveforms and simulation waveforms, the correctness and effectiveness of the theory can be verified. The whole system can realize active and reactive power grid connection in the cascade state of modules.

\section{Conclusions}

Based on the research background of cascade utilization of repurposed batteries in power energy storage system, a series of analysis and research on RBES system based on CPET were carried out in this paper. The topological structure and control strategy of DC-AC stage and DC-DC stage in this system were analyzed.

CPET is composed of current fed dual active bridge modules and $\mathrm{H}$-bridge module. AC side can be directly connected to the medium and high voltage power grid, and low-voltage side has an independent DC output end. The hierarchical control strategy of the RBES system based on CPET is composed of the energy layer, the power layer, and the SOC layer. The energy layer responds to the active and reactive scheduling instructions, the power layer controls the grid-connected current and tracks the grid voltage, and the SOC layer equates the charged state of repurposed batteries.

\section{Data Availability}

The data used to support the findings of this study were supplied by Jiaxun Teng under license and so cannot be made freely available. Requests for access to these data should be made to Jiaxun Teng (tengjiaxun@qq.com).

\section{Conflicts of Interest}

The authors declare that there are no conflicts of interest regarding the publication of this study.

\section{Acknowledgments}

This work was funded by the Science and Technology Project of State Grid Corporation of China "Research funding of energy Internet multi-energy flow integration and routing technology based on multi-port energy router."

\section{References}

[1] O. O. Mengi and I. H. Altas, "A new energy management technique for $\mathrm{PV} /$ wind/grid renewable energy system,"
International Journal of Photoenergy, vol. 2015, Article ID 356930, 19 pages, 2015.

[2] T. Cheng, M. Chen, Y. Wang et al., "Adaptive robust method for dynamic economic emission dispatch incorporating renewable energy and energy storage," Complexity, vol. 2018, Article ID 2517987, 13 pages, 2018.

[3] R. Zhu, A. L. Zhao, G. C. Wang, X. Xia, and Y. Yang, "An energy storage performance improvement model for gridconnected wind-solar hybrid energy storage system," Computational Intelligence and Neuroscience, vol. 2020, Article ID 8887227, 10 pages, 2020.

[4] L. Chen, Li Ren, L. Zhu, T. Wang, and Y. Li, "Wind generation systems including energy storage," International Journal of Rotating Machinery, vol. 2017, Article ID 7424812, 9 pages, 2017.

[5] A. Cavallo, G. Canciello, and B. Guida, "Energy storage system control for energy management in advanced aeronautic applications," Mathematical Problems in Engineering, vol. 2017, Article ID 4083132, 9 pages, 2017.

[6] R. Singh, S. Taghizadeh, N. M. L. Tan, and J. Pasupuleti, "Battery energy storage system for PV output power leveling," Advances in Power Electronics, vol. 2014, Article ID 796708, 11 pages, 2014.

[7] S. Jin, Z. Mao, H. Li, and W. Qi, "Dynamic operation management of a renewable microgrid including battery energy storage," Mathematical Problems in Engineering, vol. 2018, Article ID 5852309, 19 pages, 2018.

[8] W.-Y. Chang, "The state of charge estimating methods for battery: a review," International Scholarly Research Notices, vol. 2013, Article ID 953792, 12 pages, 2013.

[9] J. Gonçalves de Oliveira and H. Bernhoff, "Battery recharging issue for a two-power-level flywheel system," Journal of Electrical and Computer Engineering, vol. 2010, Article ID 470525, 5 pages, 2010.

[10] B. Yu, "Design and experimental results of battery charging system for microgrid system," International Journal of Photoenergy, vol. 2016, Article ID 7134904, 6 pages, 2016.

[11] Y. Han, J. Wang, Q. Zhao, and P. Han, "An optimal operating strategy for battery life cycle costs in electric vehicles," Journal of Applied Mathematics, vol. 2014, Article ID 305905, 6 pages, 2014.

[12] S. Y. Kim and G.-I. Kwon, "Interrupt-based step-counting to extend battery life in an activity monitor," Journal of Sensors, vol. 2016, Article ID 5824523, 6 pages, 2016.

[13] E. Yao, M. Wang, Y. Song, and Y. Yang, "State of charge estimation based on microscopic driving parameters for electric vehicle's battery," Mathematical Problems in Engineering, vol. 2013, Article ID 946747, 6 pages, 2013.

[14] L. Chen, K. Qian., M. Qin., X. Xu., and Y. Xia., “A configuration-control integrated strategy for electric bus charging 
station with echelon battery system," IEEE Transactions on Industry Applications, vol. 56, no. 5, pp. 6019-6028, 2020.

[15] T. Zhao, J. Jiang, C. Zhang, K. Bai, and N. Li, "Robust online state of charge estimation of lithium-ion battery pack based on error sensitivity analysis," Mathematical Problems in Engineering, vol. 2015, Article ID 573184, 11 pages, 2015.

[16] Y. Wei, S. Dai, J. Wang, Z. Shan, and J. Min, "Switch matrix algorithm for series lithium battery pack equilibrium based on derived acceleration information gauss-seidel," Mathematical Problems in Engineering, vol. 2019, Article ID 8075453, 9 pages, 2019.

[17] H. Hasabelrasul, X. Yan, and A. S. Gadalla, "Cascaded H-bridge multilevel inverter balancing for energy-power based on VSG," in Proceedings of the 2019 International Conference on Computer, Control, Electrical, and Electronics Engineering (ICCCEEE), pp. 1-5, Khartoum, Sudan, 2019.

[18] X. Yan. and H. Hasabelrasul, "Active power analysis for the battery energy storage systems based on a modern cascaded multilevel converter," in Proceedings of the 2018 IEEE International Conference on Energy Internet (ICEI), pp. 111-116, Beijing, China, 2018.

[19] A. Moeini. and S. Wang, "The State of charge balancing techniques for electrical vehicle charging stations with cascaded H-bridge multilevel converters," in Proceedings of the 2018 IEEE Applied Power Electronics Conference and Exposition (APEC), pp. 637-644, San Antonio, TX, USA, 2018.

[20] T. Hu., L. Xu., L. Qiu., Y. Li, and X. Han, "A hybrid converter for energy management of EV drives," in Proceedings of the 2015 IEEE Applied Power Electronics Conference and Exposition (APEC), pp. 3132-3137, Charlotte, North Carolina, 2015.

[21] K. Kandasamy, D. M. Vilathgamuwa, and G. Foo, "Intermodule SoC balancing control for CHB based BESS using multi-dimensional modulation," in Proceedings of the 2013 IEEE International Conference on Industrial Technology (ICIT), pp. 1630-1635, Cape Town, South Africa, 2013. 